\title{
The Shared Savings Contract Online Supply Chain Inventory and Transportation Optimization Model Research
}

\author{
Ying Chen ${ }^{1, a}$ and Yonghua Yang ${ }^{2, b}$ \\ ${ }^{1}$ School of Economics and Management, Yunnan Normal University, Kunming 650500, China; \\ ${ }^{2}$ School of Economics and Management, Yunnan Normal University, Kunming 650500, China. \\ a2508428618@qq.com, byhyang2003@163.com
}

Keywords: Shared savings, third-party logistics, outsourcing, Game.

\begin{abstract}
In the traditional logistics outsourcing contract, inventory and transportation cost is higher, is not conducive to bilateral cooperation. Through this study, the results show that the joint optimization decisions based on shared savings contract mode, the partners and the overall system is better than the decentralized decision-making model of profit margins, and in decentralized decision-making model and joint optimization decision-making mode, e-commerce supply chain optimization based on shared savings contract are better than the traditional logistics outsourcing contract is more advantageous to both sides of the cooperation.
\end{abstract}

\section{Introduction}

In the e-commerce supply chain, the emergence of third-party logistics service providers (TPLSP) provides an effective way for network retailer to save logistics costs. To save logistics costs, network retailer and TPLSP can from their own interests, through their own efforts to save logistics costs, to achieve decentralized supply chain optimization. But also through the joint efforts of both sides to save the supply chain logistics costs, to achieve the overall optimization of the supply chain. However, TPLSP revenue growth depends on the growth of logistics costs of network retailers, so the third-party logistics service providers are reluctant to take the initiative to take the overall optimization strategy. In order to solve the conflict of interest between network retailer and TPLSP, the two parties can achieve an effective logistics outsourcing contract, so as to minimize the friction or conflict of interests, and achieve the win-win situation.

The scholars have already carried on certain research to the logistics outsourcing contract design question. For example, In [1], through the establishment of the coordination mechanism, the real option contract is introduced to analyze the change of supplier's profit and government cost. [2] studied the retailer-led pricing strategy of fresh agricultural products supply chain retailers earnings impact. In addition, some scholars use the repurchase [3], sales rebates [4], revenue sharing [5] and other co-ordination between the parties to coordinate the distribution of benefits. However, the existing research did not apply the shared-saving ideas to the online shopping supply chain. Based on the online shopping supply chain, this paper adopts the game analysis method to analyze the common decentralized decision-making mode and centralization of the common logistics outsourcing contracts and shared. The paper analyzes the influence of network retailer and TPLSP cooperation on the cooperation and the overall performance of the system. Finally, the feasibility of the research is verified by an example.

\section{Model Assumptions and Conditions}

Assumption 1: In the imperfectly competitive market, TPLSP provides logistics services for online retailer. The nominal prices of goods sold by online retailer are marked. According to the price leadership model, it is assumed that network retailer is market price leader.

Assumption 2: There is no stock in the network retailer, the supplier can supply the goods in time according to the demand of the market. There is no out-of-stock phenomenon, and the logistics 
service cost is borne by the network retailer.

Assumption 3: The demand for the retailer's goods is Q, and the relationship between the demand $\mathrm{Q}$ and the price $\mathrm{P}$ is: $\mathrm{Q}=\mathrm{a}-\mathrm{bp}$, and the coefficients $\mathrm{a}, \mathrm{b}>0 ; \mathrm{p} \geq 0$.

Assumption 4: In order to save the logistics cost, the efforts of the network retailer and TPLSP are respectively $e_{c}, e_{i}$, where $e_{c}, e_{i} \in[0,1]$ The joint logistics cost of the network retailer and TPLSP is $\Delta \mathrm{C}_{\mathrm{L}}\left(\mathrm{e}_{\mathrm{C}}, \mathrm{e}_{\mathrm{i}}\right)$ in $[0,1] \times[0,1], \Delta \mathrm{C}_{\mathrm{L}}\left(\mathrm{e}_{\mathrm{C}}, \mathrm{e}_{1}\right)$ is second-order differentiable, and $\Delta \mathrm{C}_{\mathrm{L}}\left(\mathrm{e}_{\mathrm{L}}, \mathrm{e}_{1}\right)$ meet the following conditions: $\Delta \mathrm{C}_{\mathrm{L}}\left(0, \mathrm{e}_{\mathrm{l}}\right)=\Delta \mathrm{C}_{\mathrm{L}}\left(\mathrm{e}_{\mathrm{c}}, 0\right)=0$, said that as long as any party does not pay efforts, no matter how the other party can not save the cost of logistics costs, only the joint efforts of both parties in order to achieve the purpose of saving logistics costs. $\partial \Delta \mathrm{C}_{\mathrm{L}}\left(\mathrm{e}_{\mathrm{C}}, \mathrm{e}_{\mathrm{l}}\right) / \partial \mathrm{e}_{\mathrm{c}}>0, \partial \Delta \mathrm{C}_{\mathrm{L}}\left(\mathrm{e}_{\mathrm{C}}, \mathrm{e}_{\mathrm{l}}\right) / \partial \mathrm{e}_{\mathrm{l}}>0$, that with the online retailer and TPLSP effort to increase the cost of logistics will gradually increase savings; $\partial^{2} \Delta \mathrm{C}_{\mathrm{L}}\left(\mathrm{e}_{\mathrm{C}}, \mathrm{e}_{1}\right) / \partial \mathrm{e}_{\mathrm{C}}^{2}<0, \partial^{2} \Delta \mathrm{C}_{\mathrm{L}}\left(\mathrm{e}_{\mathrm{C}^{\prime}} \mathrm{e}_{\mathrm{l}}\right) / \partial \mathrm{e}_{1}^{2}<0$, It means that the saving rate of logistics cost will decrease with the increase of effort $e_{c}, e_{1}$.

Assumption 5: Due to the logistics cost savings, network retailer and TPLSP need to pay the cost of effort $\mathrm{C}_{\mathrm{C}}\left(\mathrm{e}_{\mathrm{C}}\right), \mathrm{C}_{\mathrm{L}}\left(\mathrm{e}_{\mathrm{l}}\right)$. where $\mathrm{C}_{\mathrm{C}}\left(\mathrm{e}_{\mathrm{C}}\right), \mathrm{C}_{\mathrm{L}}\left(\mathrm{e}_{\mathrm{l}}\right) \in[0,+\infty), \mathrm{C}_{\mathrm{C}}\left(\mathrm{e}_{\mathrm{C}}\right), \mathrm{C}_{\mathrm{L}}\left(\mathrm{e}_{\mathrm{q}}\right)$ meet the following conditions: $\mathrm{C}_{\mathrm{c}}(0)=\mathrm{C}_{\mathrm{l}}(0)=0$, said that the cost is zero when the network retailer and TPLSP do not work ; $\lim _{\mathrm{e}_{\mathrm{C}} \rightarrow 1} \mathrm{C}_{\mathrm{C}}\left(\mathrm{e}_{\mathrm{C}}\right)=+\infty, \lim _{\mathrm{e}_{\mathrm{T}} \rightarrow 1} \mathrm{C}_{\mathrm{L}}\left(\mathrm{e}_{\mathrm{l}}\right)=+\infty$, it means that the cost paid by network retailer and TPLSP is huge when the effort is close to 1 ;

The related symbols are explained as follows: $\mathrm{p}$ is the retailer's sales price; $\mathrm{Q}$ is the market demand for the network retailer's commodity; $\mathrm{c}_{\mathrm{p}}$ is the unit commodity cost of the network retailer; $\mathrm{p}_{1}$ is the TPLSP provides the commodity service quotation; TPLSP provides the logistics cost per unit of goods $c_{1}$ and $p_{1}>c_{1} . e_{c}$ for the network retailer to reduce the logistics costs to the extent of effort; $e_{1}$ for the TPLSP to reduce the cost of logistics efforts, ande $\mathrm{e}_{\mathrm{C}^{\prime}} \mathrm{e}_{\mathrm{i}} \in[0,1] ; \Delta \mathrm{C}_{\mathrm{L}}\left(\mathrm{e}_{\mathrm{L}^{\prime}} \mathrm{e}_{\mathrm{i}}\right)$ for network retailer and TPLSP; $\mathrm{c}_{\mathrm{c}}\left(\mathrm{e}_{\mathrm{c}}\right)$ for the network retailer to save logistics costs for the efforts of the cost; $\mathrm{c}_{\mathrm{L}}\left(\mathrm{e}_{\mathrm{l}}\right)$ for the TPLSP to save logistics costs of the effort costs.

\section{Basic Model}

\subsection{Traditional Logistics Outsourcing Contract}

In real life, the traditional logistics outsourcing contract can be expressed as the network retailer on TPLSP transfer payments: $T\left(\mathrm{C}_{\mathrm{CF}}, \mathrm{p}_{\mathrm{l}}, \mathrm{Q}\right)=\mathrm{C}_{\mathrm{CF}}+\mathrm{p}_{\mathrm{l}} \mathrm{Q}$, Where $\mathrm{C}_{\mathrm{CF}}$ is the logistics cost paid by the network retailer to the fixed portion of the TPLSP. $\mathrm{C}_{\mathrm{LF}}$ TPLSP in order to obtain a fixed income $\mathrm{C}_{\mathrm{CF}}$ and the cost to be paid, $\mathrm{C}_{\mathrm{CF}} 、 \mathrm{C}_{\mathrm{LF}}$ are not subject to change in the number of goods change, and $\mathrm{C}_{\mathrm{CF}} \geq \mathrm{C}_{\mathrm{LF}} \geq 0$.

\subsection{Decentralized Decision Model}

Decentralized decision-making model, the network retailer and TPLSP are independent of each other's decision-making body, respectively, to maximize their own decision-making, online retailers have the right to make decisions on prices. First of all, TPLSP will provide the network retailer with the logistics service price per unit of goods; then the network retailer according to their own interests to maximize the unit of goods provided by the TPLSP to determine the price of logistics services, and then decide Whether to accept TPLSP offer. Should the agreement be accepted, the TPLSP will re-quote it until the parties reach an agreement or terminate the contract. The decentralized decision-making model in the network the maximum profit for retailer: $\pi_{c}(p)_{1}=\frac{b}{a n}\left(\frac{c}{a}-c_{p}-c_{1}\right)^{2}-c_{C F}$, The

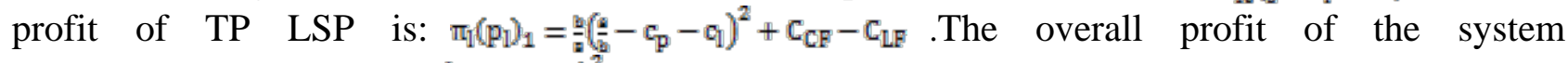
is: $\pi_{\mathrm{T}}(\mathrm{p})_{1}=\pi_{\mathrm{c}}(\mathrm{p})_{1}+\pi_{1}\left(\mathrm{p}_{\mathrm{P}}\right)_{1}=\frac{\mathrm{nh}}{\mathrm{n}}\left(\frac{\mathrm{c}}{\mathrm{a}}-\mathrm{c}_{\mathrm{p}}-\mathrm{c}_{\mathrm{l}}\right)^{2}-\mathrm{C}_{\mathrm{LF}}$.

\subsection{Joint Decision Model}

The network retailer and TPLSP as a system, from the system to maximize the interests of the overall decision-making, this decision-making model is called joint decision-making model. The overall profit of network retailer, TP LSP, system under joint decision mode are: $\pi_{\mathrm{c}}(\mathrm{p})_{2}=\frac{\mathrm{b}}{4}\left(\mathrm{e}-\mathrm{c}_{\mathrm{p}}-\mathrm{c}_{\mathrm{l}}\right)^{2}-\mathrm{C}_{\mathrm{CF}}, \pi_{1}\left(\mathrm{p}_{1}\right)_{2}=\mathrm{C}_{\mathrm{CF}}-\mathrm{C}_{\mathrm{LF}}, \pi_{\mathrm{T}}(\mathrm{p})_{2}=\pi_{\mathrm{c}}(\mathrm{p})_{2}+\pi_{1}\left(\mathrm{p}_{1}\right)_{2}=\frac{\mathrm{b}}{4}\left(\mathrm{e}-\mathrm{c}_{\mathrm{p}}-\mathrm{c}_{\mathrm{l}}\right)^{2}-\mathrm{C}_{\mathrm{LF}}$. From the above we can see that the traditional logistics outsourcing contract in the joint decision-making model of online retailer profit $\pi_{c}(\mathrm{p})_{2}$ is greater than the decentralized decision-making mode of network retailer profit $\pi_{c}(\mathrm{p})_{1}$ The profit of the whole system is bigger than the profit of the whole 
system under decentralized decision-making mode .Profit $\pi_{1}\left(\mathrm{p}_{1}\right)_{2}$ of TPLSP under joint decision mode is smaller than that of TPLSP in decentralized decision mode, which shows that the profit of network retailer and the profit of system as a whole are optimized compared with decentralized decision mode. TPLSP profit is losses, which is not conducive to TPLSP and network retailer to form a stable and cooperative relations. In order to solve this problem, TPLSP actively adopts joint optimization decision, which needs to distribute the profit of the system properly, so that the profits of both parties are increased. Sharing the contract is an effective tool to coordinate the profit distribution of both parties.

\section{Shared Saving Model}

\subsection{Shared Savings Contract}

In order to motivate TPLSP and online retailer to work together to save logistics costs, network retailer needs to increase the cost of logistics cost savings $(1-\theta)$ to TPLSP . if $\theta=1$, it means that the network retailer will take up all the logistics costs alone, then the TPLSP will not want to work hard, and can not achieve the purpose of saving logistics costs; Conversely, if $\theta=0$, TPLSP will enjoy the savings alone cost, at this time, the network retailers are reluctant to make any efforts, so it will not be able to achieve the purpose of reducing logistics costs. Therefore, $\theta \in(0,1)$.

\subsection{Game Analysis of Shared Savings Contract}

Network retailer have decision-making power on the price, the two sides of the game process is as follows: First, the network retailer and TPLSP agreement to determine the fixed part of the logistics costs and share their savings in the proportion of logistics costs; Second, TPLSP selection to the network retailer to provide logistics services unit price of goods and logistics and transportation efforts level; Finally, the network retailer to maximize their own interests as a criterion, the unit of goods provided by the TPLSP price of logistics services and logistics and transport efforts to analyze the level and determine whether the offer is reasonable, and then decide whether to accept TPLSP offer. If accepted, the agreement between the two parties is reached; if rejected, TPLSP will requote until the two sides reach an agreement or terminate the contract. Sharing the profit function of network retailer in contract:

$$
\pi_{\mathrm{C}}\left(\mathrm{p}, \mathrm{e}_{\mathrm{c},}, \mathrm{e}_{\mathrm{l}}\right)=\left[\mathrm{p}-\mathrm{c}_{\mathrm{p}}-\mathrm{p}_{\mathrm{l}}+\theta \Delta \mathrm{C}_{\mathrm{L}}\left(\mathrm{e}_{\mathrm{c},}, \mathrm{e}_{\mathrm{l}}\right)\right] \mathrm{Q}-\mathrm{C}_{\mathrm{C}}\left(\mathrm{e}_{\mathrm{C}}\right)-\mathrm{C}_{\mathrm{CF}}
$$

When $\partial \pi_{\mathrm{c}}\left(\mathrm{p}, \mathrm{e}_{\mathrm{c}}, \mathrm{e}_{\mathrm{l}}\right) / \partial \mathrm{p}=0$, the existence of a unique optimal price levelp ${ }^{*}$ allows the network retailer to maximize profits. So

$$
\mathrm{p}^{*}=\frac{1}{2}\left[\frac{\mathrm{a}}{\mathrm{b}}+\mathrm{c}_{\mathrm{p}}+\mathrm{p}_{1}-\theta \Delta \mathrm{C}_{\mathrm{L}}\left(\mathrm{e}_{\mathrm{c}}, \mathrm{e}_{\mathrm{l}}\right)\right]
$$

The profit function of the TSP in the Shared Savings Contract is:

$$
\pi_{\mathrm{L}}\left(\mathrm{p}_{\mathrm{l}}, \mathrm{e}_{\mathrm{e}^{2}}, \mathrm{e}_{\mathrm{l}}\right)=\left[\mathrm{p}_{\mathrm{l}}-\mathrm{c}_{\mathrm{l}}+(1-\theta) \Delta \mathrm{C}_{\mathrm{L}}\left(\mathrm{e}_{\mathrm{C}}, \mathrm{e}_{\mathrm{l}}\right)\right] \mathrm{Q}-\mathrm{C}_{\mathrm{L}}\left(\mathrm{e}_{\mathrm{l}}\right)+\mathrm{C}_{\mathrm{CF}}-\mathrm{C}_{\mathrm{LF}}
$$

When $\partial \pi_{\mathrm{L}}\left(\mathrm{p}_{1}, \mathrm{e}_{\mathrm{c}}, \mathrm{e}_{1}\right) / \partial \mathrm{p}_{\mathrm{l}}=0$.The existence of a unique optimal price levelp ${ }^{*}$ allows the network retailer to maximize profits. So

$$
\mathrm{p}_{\mathrm{i}}^{*}=\frac{2}{2}\left[\mathrm{e}_{\mathrm{w}}-\mathrm{c}_{\mathrm{p}}+\mathrm{c}_{\mathrm{l}}-(1-2 \theta) \Delta \mathrm{C}_{\mathrm{L}}\left(\mathrm{e}_{\mathrm{c}}, \mathrm{e}_{\mathrm{i}}\right)\right]
$$

Respectively for the partial derivative on $\theta$ for the (6), (8) formula,

$$
\begin{gathered}
\partial \mathrm{p}^{*} / \partial \theta=-\left[\Delta \mathrm{C}_{\mathrm{L}}\left(\mathrm{e}_{\mathrm{C}}, \mathrm{e}_{\mathrm{l}}\right) / 2\right]<0 \\
\partial \mathrm{p}_{\mathrm{l}}^{*} / \partial \theta=\Delta \mathrm{C}_{\mathrm{L}}\left(\mathrm{e}_{\mathrm{C}}, \mathrm{e}_{\mathrm{l}}\right)>0
\end{gathered}
$$

From equation (9), we can see that the higher the proportion of logistics cost shared by network retailer, the lower the intrinsic power of unit price. As can be seen from (10), when TPLSP share the higher proportion of logistics cost, The more the lower the price of goods logistics services will.

\subsection{Decentralized Decision-making Mode in Shared Contract}

In the non-cooperative game, both the network retailer and the TP LSP make their own decisions from the perspective of maximizing their own interests.

When p, $\mathrm{p}_{1}$ are invariable, $\mathrm{p}=\mathrm{p}^{*}{ }_{\mathrm{v}} \mathrm{p}_{\mathrm{l}}=\mathrm{p}_{\mathrm{l}}^{*}$. In (5) When $\partial \pi_{\mathrm{c}}\left(\mathrm{e}_{\mathrm{c}^{2}} \mathrm{e}_{\mathrm{l}}\right) / \partial \mathrm{e}_{\mathrm{c}}=0$, there is a unique optimal solution one $\mathrm{e}_{\mathrm{c}} \in[0,1]: \mathrm{e}_{\mathrm{C}_{1}}=\operatorname{argmax} \pi_{\mathrm{C}}\left(\mathrm{e}_{\mathrm{C}}, \mathrm{e}_{\mathrm{l}}\right)$.Similarly, $\operatorname{in}(7)$ When $\partial \pi_{\mathrm{L}}\left(\mathrm{e}_{\mathrm{C}^{\prime}}, \mathrm{e}_{\mathrm{l}}\right) / \partial \mathrm{e}_{\mathrm{l}}=0$, there is a unique optimal solution one $e_{1} \in[0,1]: e_{l_{1}}=\operatorname{argmax} \pi_{L}\left(e_{\mathrm{c}}, e_{1}\right)$. From the above we can see that the efforts of online retailer and TPLSP game Nash equilibrium is $\left(\mathrm{e}_{\mathrm{c}_{1}}, e_{\mathrm{e}_{1}}\right)$, that is, based on shared savings contract 
decentralized decision-making mode, network retailer and TPLSP are not willing to deviate from its optimal effort level. At this point, the largest network of retailer profit $\pi_{\mathrm{c}}\left(\mathrm{p}^{*}, \mathrm{e}_{\mathrm{c}_{1},}, \mathrm{e}_{\mathrm{l}_{1}}\right)$, TPLSC maximum profit of $\pi_{\mathrm{L}}\left(\mathrm{p}_{1}^{*}, \mathrm{e}_{\mathrm{c}_{1}}, \mathrm{e}_{\mathrm{l}_{1}}\right)$.

\subsection{Joint Decision - making Mode in Shared Savings Contract}

In the joint decision mode, the network retailer and TP LSP are regarded as a whole system. The profit function of the whole system is:

$$
\pi_{\mathrm{T}}\left(\mathrm{p}, \mathrm{e}_{\mathrm{C}}, \mathrm{e}_{1}\right)=\left[\mathrm{p}-\mathrm{c}_{\mathrm{p}}-\mathrm{c}_{1}+\Delta \mathrm{C}_{\mathrm{L}}\left(\mathrm{e}_{\mathrm{c}}, \mathrm{e}_{\mathrm{l}}\right)\right] \mathrm{Q}-\mathrm{c}_{\mathrm{C}}\left(\mathrm{e}_{\mathrm{C}}\right)-\mathrm{C}_{\mathrm{L}}\left(\mathrm{e}_{\mathrm{l}}\right)-\mathrm{C}_{\mathrm{LF}}
$$

In order to maximize the overall profit of the system, network retailer and TPLSP need to choose their own optimal effort, and satisfy $\left(e_{c}, e_{1}\right) \in[0,1]$.Given $p$ unchanged, that is $p=p^{*}$. In(11) when $\partial \pi_{\mathrm{T}}\left(\mathrm{e}_{\mathrm{C}}, \mathrm{e}_{1}\right) / \partial \mathrm{e}_{\mathrm{c}}=0$, there is a unique optimal solution on $\mathrm{e}_{\mathrm{C}} \in[0,1]: \mathrm{e}_{\mathrm{C}_{2}}=\operatorname{argmax} \pi_{\mathrm{T}}\left(\mathrm{e}_{\mathrm{C}}, \mathrm{e}_{1}\right)$ Similarly, when $\pi_{\mathrm{T}}\left(\mathrm{e}_{\mathrm{c}}, \mathrm{e}_{1}\right) / \partial \mathrm{e}_{\mathrm{l}}=0$, there is a unique optimal solution on $\mathrm{e}_{\mathrm{l}} \in[0,1]: \mathrm{e}_{\mathrm{l}_{2}}=\operatorname{argmax} \pi_{\mathrm{T}}\left(\mathrm{e}_{\mathrm{c}^{2}}, \mathrm{e}_{1}\right)$. Therefore, the system as a whole at this time the maximum profit for $\pi_{\mathrm{T}}\left(\mathrm{p}^{*}, \mathrm{e}_{\mathrm{C}_{2}}, \mathrm{e}_{\mathrm{I}_{2}}\right)$ the profits of the network retailer $\pi_{\mathrm{C}}\left(\mathrm{p}^{*}, \mathrm{e}_{\mathrm{C}_{2}}, \mathrm{e}_{\mathrm{l}_{2}}\right), \mathrm{TPLSP}$ profit for the $\pi_{\mathrm{L}}\left(\mathrm{p}_{1}^{*}, \mathrm{e}_{\mathrm{C}_{2}}, \mathrm{e}_{\mathrm{V}_{2}}\right)$.

From the above we can see that in order to make the profits of network retailer and TPLSP have improved, take the initiative to cooperate with the sharing of savings based on the joint optimization of the contract, the profit function of both sides should meet the following conditions: $\left\{\begin{array}{l}\pi_{\mathrm{C}}\left(\mathrm{p}^{*}, \mathrm{e}_{\mathrm{e}_{2},}, \mathrm{e}_{\mathrm{l}_{2}}\right)>\pi_{\mathrm{C}}\left(\mathrm{p}^{*}, \mathrm{e}_{\mathrm{C}_{1},}, \mathrm{e}_{\mathrm{l}_{1}}\right) \\ \pi_{\mathrm{L}}\left(\mathrm{p}_{1}^{*}, \mathrm{e}_{\mathrm{C}_{2},}, \mathrm{e}_{\mathrm{l}_{2}}\right)>\pi_{\mathrm{L}}\left(\mathrm{p}_{1}^{*}, \mathrm{e}_{\mathrm{C}_{1},}, \mathrm{e}_{\mathrm{l}_{1}}\right)\end{array}\right.$, therefore,

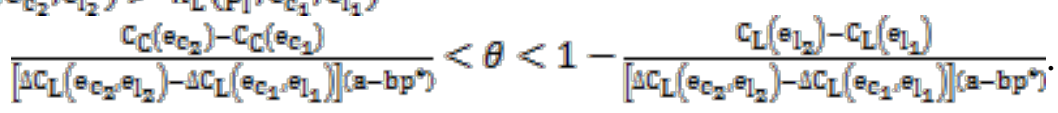

Therefore, in the online shopping supply chain considering the shared savings contract, when the network retailer share the proportion of cost savings in the above range, both parties are willing to work together to save the logistics cost, and the profits of both parties are better than the common logistics .The profit and partnership in the outsourcing contract are stable and sustainable.

\section{Case Study}

Suppose a commodity's market demand and price as a function of the relationship between the formula: $\quad \mathrm{Q}=1000-4 \mathrm{p}, \quad \mathrm{cp}=50, \quad \mathrm{c}_{1}=4, \mathrm{C}_{\mathrm{CF}}=300, \mathrm{C}_{\mathrm{LF}}=200$ $\Delta \mathrm{C}_{\mathrm{L}}\left(\mathrm{e}_{\mathrm{C}}, \mathrm{e}_{\mathrm{l}}\right)=5\left(-\mathrm{e}_{\mathrm{c}}^{2}+5 \mathrm{e}_{\mathrm{c}}\right)\left(-\mathrm{e}_{1}^{2}+\mathrm{e}_{\mathrm{l}}\right), \mathrm{C}_{\mathrm{C}}\left(\mathrm{e}_{\mathrm{c}}\right)=5\left[\left(1-\mathrm{e}_{\mathrm{c}}\right)^{-1}-\mathrm{e}_{\mathrm{c}}-1\right], \mathrm{C}_{\mathrm{L}}\left(\mathrm{e}_{\mathrm{l}}\right)=5\left[\left(1-\mathrm{e}_{1}\right)^{-1}-\mathrm{e}_{1}-1\right] \cdot$ Through the calculated: In the common logistics outsourcing contract, $\pi_{\mathrm{C}}(\mathrm{p})_{1}=9304, \pi_{\mathrm{L}}\left(\mathrm{p}_{1}\right)_{1}=19308, \pi_{\mathrm{T}}(\mathrm{p})_{1}=28612$; In the joint optimization decision-making mode, $\pi_{\mathrm{C}}(\mathrm{p})_{2}=38116, \pi_{\mathrm{L}}\left(\mathrm{p}_{1}\right)_{2}=100, \pi_{\mathrm{L}}(\mathrm{p})_{2}=38216$. We can see that in the joint optimization decision mode, the profits of the network retailer and the overall profit of the system increase by 28812,9604 respectively, while the TPLSP loss of 19208, resulting in a significant reduction in TPLSP profits, will affect the two sides Cooperation. By introducing the shared savings contract and as $\theta=0.6080$, it can be concluded that $\pi_{\mathrm{C}}\left(\mathrm{p}^{*}, \mathrm{e}_{\mathrm{C}_{1},}, \mathrm{e}_{\mathrm{l}_{1}}\right)=9652.56806 \quad, \quad \pi_{\mathrm{L}}\left(\mathrm{p}_{1}^{*}, \mathrm{e}_{\mathrm{C}_{1}}, \mathrm{e}_{\mathrm{l}_{1}}\right)=19721.71448$, $\pi_{\mathrm{T}}\left(\mathrm{p}^{*}, \mathrm{e}_{\mathrm{C}_{1},}, e_{\mathrm{l}_{1}}\right)=29374.28254$. In the joint optimization decision mode, it can be concluded that $\pi_{\mathrm{C}}\left(\mathrm{p}^{*}, \mathrm{e}_{\mathrm{C}_{2}}, \mathrm{e}_{\mathrm{l}_{2}}\right)=9704.8369, \pi_{\mathrm{L}}\left(\mathrm{p}_{1}^{*}, \mathrm{e}_{\mathrm{C}_{2}}, \mathrm{e}_{\mathrm{l}_{2}}\right)=19759.71965, \pi_{\mathrm{T}}\left(\mathrm{p}^{*}, \mathrm{e}_{\mathrm{C}_{2}}, \mathrm{e}_{\mathrm{l}_{2}}\right)=29464.55654$.

Thus, the profits of network retailer, TPLSP and system as a whole are 52.26884, 38.00517 and 90.274 higher than that of decentralized decision-making mode, respectively, compared with the joint optimization and decentralized decision-making model. Retailer , TPLSP and system as a whole have been Pareto optimization of the profits, and with the traditional logistics outsourcing contract, the introduction of shared savings after the contract the two sides of the profit distribution of the two sides can promote further cooperation.

\section{Conclusions}

In the traditional logistics contract online shopping supply chain, network retailer and TPLSP are from the self-interest decision-making, it is difficult to effectively stimulate the TPLSP and network 
retailer together to save logistics costs, although in the joint optimization decision-making mode network retailer and systems overall profit has increased, but the profits of TPLSP will suffer losses, is not conducive to the maintenance of bilateral cooperation. In order to stimulate TPLSP and network retailers to work together to conserve logistics costs, the introduction of shared savings contracts, network retailer will save logistics costs due to the system revenue increase in accordance with the sharing of savings in the proportion of the parameters specified in the transfer to the TPLSP, the results show that Under the model of joint optimization, the profit of both partners and the system is better than that of the decentralized decision mode. Chain optimization than the traditional logistics outsourcing contract is more conducive to cooperation between the two sides.

\section{Acknowledgments}

Corresponding author of this work is Yonghua Yang.This work is supported by Department of Science and Technology of Yunnan Province under grant number 2016FB118.

\section{References}

[1] TLAN JUN, GE Yong-ling, HOU Cong-cong. Government-driving emergency supplies procurement model based on real option contract [J]. Systems Engineering-Theory \& Practices,2014,34(10):2582-2590.

[2] LI Lin, FAN Ti-jun. Comparison and analysis on Pricing Policies for Fresh Agricultural Produce Supply Chain with Dominant Retailer [J]. Chinese Journal of Management Science,2015,23(12):113-123.

[3] Krishnan H, Kapuscinski R, Butz DA . Coordinating Contracts for Decentralized Supply Chains with Retailer Promotional Effort [J].Management Science, 2004, 50( 1) : 48-63.

[4] Taylor TA. Supply chain coordination under channel rebates with sales effort effects[ J] . Management Science, 2002, 48( 8) : 992-1007.

[5] SUN Yu-ling, HONG Mei-na, SHI Kui-ran. Revenue Sharing Contract of Supply Chain for Fresh Agricultural Products Considering Fairness Concerns[J]. Operations Research and Management Science,2015,24(6):103-111. 